\title{
ENTREVISTA COM A PSICÓLOGA, SEXÓLOGA E POLICIAL CIVIL YEDA MARIA AGUIAR PORTELA
}

\author{
por Ana Canosa
}

Yeda Maria Aguiar Portela (Yeda Portela) é psicóloga clínica, sexóloga, professora, mestre em Sexologia, doutora em Educação, especialista em Educação Sexual, comissária de Polícia Civil, coordenadora do Projeto SAP-Mulher e vice-presidente da SBRASH.

Yeda Portela, suas profissões são psicóloga clínica, sexóloga, professora e, ainda, policial civil há muitos anos. Como foi abraçar tantas profissões?

Desde criança, sempre percebi algumas características diferenciadas na relação com o mundo e com as pessoas... Ser cuidadora, protetora e justiceira. Dava aulas para as minhas bonecas, protegia as colegas que sofriam bullying e estava sempre praticando um esporte, o que me tornava uma criança/adolescente forte. Apesar do desejo expresso de minha mãe para eu seguir na carreira de Medicina, a Psicologia foi a minha primeira e principal opção. Sou filha de dois guerreiros nordestinos e vencedores "na cidade grande", apesar de pouca instrução. Entretanto, há quase 60 anos, as relações familiares nordestinas tinham regras mais rígidas, infelizmente pautadas no machismo estrutural, que faziam com que $\circ$ desrespeito com a autonomia das mulheres prevalecesse. Percebi muito cedo que estudar seria um bom caminho para a busca de autonomia e que a leitura abria a minha mente e o meu coração para o mundo. Sentia que cuidar de uma colega de classe rejeitada era mais importante do que ser popular, que ser justa era melhor do que ser certa. $\mathrm{Na}$ juventude, descobri que namorar era muito bom e, me apaixonar, era bem melhor! Me apaixonava por amores difíceis, chorava cântaros por uma tarde toda, somente ouvindo músicas lentas nas rádios ou no gravador com fitas K7. Assim, a Psicologia entrou na minha vida como um caminho para entender o comportamento, a emocionalidade e as relações humanas. Em paralelo a minha formação e atuação em consultório, a Polícia Civil surgiu como uma oportunidade de exercer a justiça e o bem social. Identifiquei-me com a união da expertise da Psicologia com os conhecimentos técnicos de investigação, que resultaram em inúmeros sucessos com esclarecimentos de crimes. Como já era uma experiente professora para as minhas bonecas na infância, a licenciatura em Psicologia, a formação existencial-humanista e outras especializações, o mestrado em Sexologia (UGF-RJ) e o doutorado em Educação (UNR-Argentina/UNICAMP) brindaram a educadora. Até os dias atuais, procuro unir 33 anos de prática clínica, 30 anos como policial e 20 anos como sexóloga, no consultório, na sala de aula e na minha atuação na Polícia Civil do Estado do Rio de Janeiro com o Projeto SAP-Mulher: Sala de Acolhimento Psicológico para Mulheres em situação de Violência Doméstica.

Você apresentou um trabalho no IX Congresso Brasileiro sobre Estereotipias Masculinas e Disfunção Sexuais em uma pesquisa cuja amostra era composta de policiais civis. Pode contar um pouco sobre ela?

Sim, mais uma vez, uni as diferentes facetas de minha vida. Já havia feito uma pós-graduação em Sexualidade Humana (UCM-RJ) e o mestrado em Sexologia (UGF-RJ) foi um marco em minha vida por sentir que estava alinhavando definitivamente as diversas áreas de minha formação. Com a supervisão da sexóloga de excelência e coordenadora do mestrado, a Dra Maria do Carmo Andrade Silva, nossa querida "Carminha", direcionei meus estudos para entender o comportamento dos homens, já que eu tinha anos de convivência profissional com uma categoria profissional onde poucas mulheres tinham "vez e voz". Ela se apaixonou pelo projeto e com sua rigidez acadêmica, colaborou para o incremento de um importante estudo na área clínica, fundamentado teoricamente, relacionando a acentuada estereotipia masculina policial com a tendência ao desenvolvimento de disfunções sexuais. Esse mestrado estimulou-me a sair da investigação das delegacias de polícia e especializadas para a atuação clínica no Hospital da Polícia Civil Moreira Cesar (HPCMC), atualmente, Policlínica da Polícia Civil. Assim, em 2003, a Sexologia Clínica tornou-se pioneira no Hospital da Polícia Civil, oportunizando toda a classe policial a buscar tratamento especializado. Foram dez anos atuando na área com a agenda sempre preenchida, 
culminando, nos últimos anos, com a indicação para ser a responsável técnica do Setor de Saúde Mental.

Cabe aqui o destaque para a minha entrada para a Sociedade Brasileira de Estudos em Sexualidade Humana (SBRASH), pois era um sonho ser aceita como membro (2003). No ano de 20I3, fui convidada pela presidente da SBRASH, Iracema Teixeira - uma profissional e amiga de excelência -, a compor a diretoria, permanecendo nas gestões seguintes com aplicação diária (tesoureira). Hoje, com muita honra, amor e dedicação, estou, ao lado de grandes amigas na diretoria, como vice-presidente da SBRASH a convite da presidente Sheila Reis.

\section{Como e quando surgiu o Projeto SAP-MULHER?}

A Sala de Acolhimento Psicológico para Mulheres em situação de Violência Doméstica surgiu com a minha vinda para o interior do Rio de Janeiro, Região dos Lagos, e da possibilidade de abrir um serviço de psicologia especializado em atendimento clínico nos postos de polícia técnico-científica, pautado na Lei Maria da Penha. A referida Lei, no artigo $8^{\circ}$, prevê a integração operacional de diversos entes governamentais e não governamentais para empoderamento da mulher, além de implementação de atendimento policial especializado para as mulheres. Desenvolvi o projeto, apresentei para a chefia de polícia no início de 2017 e, posteriormente, legalizei-o junto ao Conselho Regional de Psicologia. O atendimento clínico teve início em junho de 2017, como um projeto pioneiro na Polícia Civil do Estado do Rio de Janeiro (PCERJ), talvez no Brasil. Acredito na importância do apoio psicológico, realizado por um psicólogo com experiência na área de Segurança Pública para empreender um tratamento qualificado e humanizado, estabelecendo relação de ajuda terapêutica pautada nos princípios de autonomia, liberdade, responsabilidade e igualdade para as mulheres em situação de violência doméstica.

\section{Qual o perfil das mulheres atendidas e como se dá o primeiro contato com o Projeto?}

São mulheres que tenham sofrido algum tipo de violência (violência doméstica e/ou sexual) e que geraram um Registro de Ocorrência. Quando as mulheres vão ao Serviço Médico Legal para fazer o Exame de Corpo de Delito são convidadas para participar do projeto. São mulheres de todas as idades (menores de idade devem ter o consentimento dos responsáveis legais). A maior frequência está na faixa etária entre 19 e 39 anos, com nível de escolaridade ensino fundamental incompleto. Entretanto, já atendi pacientes com idade que varia de cinco a setenta anos. A grande maioria coabita com o agressor (marido/ companheiro, pai, padrasto, avô). As mulheres agredidas têm, pelo menos, um(a) filho(a) com o autor, o que complexifica mais a situação. $O$ primeiro atendimento psicológico, denominado "acolhimento", é fundamental para a vítima, pois elas são ouvidas e recebem todas as orientações após o registro na delegacia de polícia, que muitas vezes, devido ao intenso estado emocional, não conseguiram assimilá-las a partir da orientação do(a) policial. Essa escuta compreensiva torna-se fundamental para que percebam que é possível ter um tratamento mais humanizado do poder público. Elas se sentem apoiadas e não desistem de dar sequência ao processo policial.

\section{Qual a importância da psicologia no trabalho com mulheres vítimas de violência nas dependências da Polícia Civil?}

É fundamental que a vítima de violência sexual/ doméstica tenha apoio psicológico para que possa: estabelecer vínculos positivos por meio da interação terapêutica; amenizar o sofrimento mental; identificar possíveis sintomas e/ou doenças psiquiátricas comuns no contexto vivido pela vítima - depressão, ameaça e/ou ideação do suicídio, automutilação, isolamento, disfunção sexual, dentre outros; favorecer a reflexão e a reelaboração de experiências vividas; fortalecer a estrutura da personalidade e a autoestima; e estimular o estabelecimento de uma rede de apoio social à vítima (familiares, amigos etc.). $\mathrm{O}$ ambiente seguro e acolhedor desse órgão público tende a proporcionar à mulher o encorajamento necessário para dar continuidade ao registro de ocorrência. Ademais, a vítima é encaminhada formalmente a buscar a Rede Municipal de Atendimento especializado às mulheres em situação de violência (tratamento médico - clínico, ginecológico, psiquiátrico; assistência social; assistência jurídica) de forma concomitante ao tratamento clínico.

\section{Com base nos atendimentos já realizados, qual caso de violência mais a chocou nesses anos à frente do projeto?}

Particularmente, todos os casos têm uma especificidade que me causa comoção, seja ela: a brutalidade física de que a mulher foi vítima; o abuso/ofensa infantil realizado por pai biológico; o cárcere privado com tortura; a subjugação perversa do ser humano; e o estresse pós-traumático sofrido pelas vítimas de violência doméstica e/ou sexual. Entretanto, há um atendimento que costumo citar por se tratar de uma senhora de 69 anos de idade e 52 anos casada, em um relacionamento abusivo/ofensivo, com inúmeros episódios de agressão física, de violência psicológica e moral. Foi marcante pois, pela primeira vez, denunciou o marido e, a partir daí, entrou para o Projeto SAP-Mulher. Iniciou o processo psicoterapêutico fragilizada e infeliz. Em oito meses de psicoterapia com assiduidade, sentiu-se segura para se separar 
do marido, romper o vínculo tóxico emocional; buscou apoio dos filhos e ressignificou a sua vida. Recentemente, a encontrei e está bem, morando com uma das filhas e desenvolvendo novos projetos em sua vida, inclusive como empreendedora.

O Projeto SAP-Mulher completou quatro anos, com mais de 360 mulheres atendidas - orientação e/ou psicoterapia - e me sinto satisfeita com os resultados obtidos, aprendendo muito a cada encontro. Por parte das vítimas, a satisfação dos resultados obtidos a partir dos atendimentos vem através de uma lágrima com um poderoso sorriso, de um forte abraço, de um sincero agradecimento e do depoimento das pacientes no processo de alta terapêutica. Em outras oportunidades, percebo os resultados obtidos no encontro informal com uma ex-paciente na feira, na rua, no comércio etc.; também, a partir do retorno de outros profissionais da rede de apoio do município: das inspetoras de polícia do Núcleo de Atendimento à Mulher (NUAM) das delegacias de polícia na região; das profissionais do Centro de Referência de Atendimento à Mulher (CRAM) e dos(as) conselheiros(as) tutelares. É muito gratificante esse trabalho, não só pelo lado profissional, já que nenhuma mulher por mim atendida no projeto foi vítima de feminicídio até a presente data; mas, pelo lado pessoal, por perceber que a minha construção pessoal - vinda de uma família batalhadora, machista e com pouca instrução - foi pautada em muita vontade de crescer; buscar a autonomia e o exercício do respeito e, principalmente, em ajudar o/a próximo/a. Acredito que, tais fatores tornam-se catalisadores na relação terapêutica, quando potencializam o processo da outra pessoa ao crescimento, sem desfazer de sua essência.

\section{Como você tem produzido conhecimento científico} a partir do Projeto SAP-Mulher? É muito importante que as pessoas tomem conhecimento do projeto e seus resultados concretos.

Quanto à produção acadêmica, há anos que o tema violência contra a mulher faz parte de minha linha de pesquisa. O Projeto SAP-MULHER tem sido apresentado como projeto-piloto da PCERJ em diversos congressos nacionais, latino-americanos e mundiais nas áreas de: sexualidade, educação, saúde e segurança pública. Nessas oportunidades, encontro com pesquisadores(as) e especialistas no tema, interessados(as) no desenho e desenvolvimento do projeto. Tem, ainda, sido a base de diversos artigos científicos e capítulos de livro publicados. Há representatividade em simpósios, encontros e grupos de estudos dos quais participo e/ou organizo. Está presente, quando eu integro na comissão da $O A B-$ Mulher e quando estou como presidente do Conselho Comunitário de Segurança em minha cidade. O objetivo maior é poder, através da educação em sexualidade e dos atendimentos clínicos orientar, educar, informar/formar e tratar o maior número possível de mulheres para que conheçam seus direitos sexuais e percebam que é possível mudar e se transformar. Novos desafios estão por vir em 2022, pois fui convidada para compor os centros de reeducação com acompanhamento psicossocial de agressores de mulheres em atenção à Lei n. 13.984/20, que estabelece como medida protetiva de urgência, a frequência do agressor a centro de educação e de reabilitação e acompanhamento psicossocial. Aí está, novamente, o "universo conspirando..."

Ana Cristina Canosa Gonçalves Psicóloga e Especialista em Sexualidade Diretora de publicações da SBRASH - biênio 2018/2022 